\title{
Isolation of a unique benzothiophene- desulphurizing bacterium, Gordona sp. strain 213E (NCIMB 40816), and characterization of the desulphurization pathway
}

\author{
Steven C. Gilbert, ${ }^{1}$ John Morton, ${ }^{1}$ Sheena Buchanan, ${ }^{1}$ \\ Christopher Oldfield' and Andrew McRoberts ${ }^{2}$ \\ Author for correspondence: Christopher Oldfield. Tel: +44 131455 2217. Fax: +44 1314552291.
e-mail: c.oldfield@napier.ac.uk
}

Department of Biological Sciences ${ }^{1}$ and Department of Applied Physical and Chemical Sciences, Napier University,2 Edinburgh EH10 5DT, UK
Gordona sp. strain $213 E$ (NCIMB 40816) grew in pure culture in a mineral salts medium containing fructose as a source of carbon and energy, and benzothiophene (BTH) as the sole source of sulphur. During growth a phenolic compound accumulated, as indicated by the production of a blue colour on addition of Gibb's reagent. Therefore this pathway is analogous to the dibenzothiophene (DBT) desulphurization pathway of Rhodococcus sp. strain IGTS8, in which 2-hydroxybiphenyl accumulates during growth with DBT as the sole sulphur source. Ethyl acetate extraction of the culture medium yielded the metabolites benzothiophene S-oxide (BTHO), benzothiophene S,S-dioxide $\left(\mathrm{BTHO}_{2}\right)$, benzo[c][1,2]oxathiin 6-oxide (BCOTO), 2-(2'-hydroxyphenyl)ethan 1-al (HPEal) and benzofuran (BFU). The deduced pathway for BTH desulphurization is $\mathrm{BTH} \rightarrow \mathrm{BTHO}^{\prime} \rightarrow \mathrm{BTHO}_{2} \rightarrow \mathrm{HPESi}^{-} \rightarrow \mathrm{HPEal}^{-} \mathrm{HPESi}^{-}$is (Z)-2-(2'-hydroxyphenyl)ethen 1-sulphinate, the stable aqueous-solution form of BcOTO. It was concluded that HPEal was the Gibb's-reagent-reactive phenolic compound which accumulated in the culture medium of strain $213 \mathrm{E}$ during growth, and that the presence of BFU was due to partial condensation of HPEal during the ethyl acetate extraction procedure. Gordona sp. strain $213 E$ was unable to grow in a mineral salts medium containing fructose as a source of carbon and energy and DBT as the sole sulphur source. BTH-desulphurization-active cells (grown using BTH as sole sulphur source) were unable to desulphurize DBT. Likewise Rhodococcus sp. strain IGTS8 was unable to grow using BTH as the sole sulphur source, and DBT-desulphurization-active cells of strain IGTS8 (grown using DBT as sole sulphur source) were unable to desulphurize BTH. This absence of crossreactivity is discussed in terms of fundamental differences in the chemistry of the DBT- and BTH-desulphurization reactions.

Keywords: Gordona sp., Rbodococcus sp., benzothiophene, desulphurizing enzymes, clean fuels

\section{INTRODUCTION}

Interest in the application of micro-organisms as a convenient and economical route to the removal of organic sulphur compounds from fossil fuels led to the discovery of Rhodococcus sp. strain IGTS8 (Kayser et al., 1993). Strain IGTS8 is able to desulphurize dibenzothiophene (DBT) to 2-hydroxybiphenyl (HBP) and inorganic sulphite (see Fig. 5b). When strain IGTS8 is grown in media containing DBT as the sole source of sulphur, DBT serves as the source of sulphur for biomass, and HBP simply accumulates in the medium

Abbreviations: BcOTO, benzo[c][1,2]oxathiin S-oxide; BeOTO, benzo[e][1,2]oxathiin S-oxide; BcOTO ${ }_{2}$, benzo[c][1,2]oxathiin S,S-dioxide; BFU, benzofuran; BPSi, dibenz $[c, e][1,2]$ oxathiin S-oxide; BTH, benzothiophene; BTHO, benzothiophene S-oxide; BTHO ${ }_{2}$, benzothiophene $S, S$-dioxide; DBT, dibenzothiophene; DBTO, dibenzothiophene $S$-oxide; $\mathrm{DBTO}_{2}$, dibenzothiophene $S, S$-dioxide; fruRM, fructose Rhodococcus medium; glyRM, glycerol Rhodococcus medium; HBP, 2-hydroxybiphenyl; HPEol, 2-(2'-hydroxyphenyl)ethen-1-ol; HPEal, 2-(2'-hydroxyphenyl)ethan-1-al; HPESi-, (Z)-2-(2'-hydroxyphenyl)ethen 1-sulphinate; HPESo-, (Z)-2-(2'-hydroxyphenyl)ethen 1-sulphonate; HBPSi', 2-hydroxybiphenyl 2'-sulphinate. 
(Kayser et al., 1993; Oldfield et al., 1997). Therefore this seems to be a sulphur-scavenging pathway. Other such pathways are known, e.g. the arylsulphatase degradation pathway of Pseudomonas aeruginosa (Beil et al., 1995) and the taurine degradation pathway of Escherichia coli (van der Ploeg et al., 1998).

DBT is widely regarded as a model compound, representative of the aromatic organosulphur fraction of coal and crude oil. Therefore DBT desulphurization by strain IGTS8 has been the subject of considerable study. The DBT-desulphurization phenotype is conferred by the plasmid-located $d s z$ operon, encoding three proteins, DszA, B and C, which are necessary and sufficient for DBT desulphurization in Rhodococcus sp. strain IGTS8 and in Escherichia coli. The operon has been cloned and sequenced (Denome et al., 1993, 1994) and the metabolic pathway has been elucidated (Olson et al., 1993; Oldfield et al., 1997). The enzymes have been purified and partially characterized (Lei \& Tu, 1996; Gray et al., 1996). Genetic analysis of the regulatory region of the $d s z$ operon indicates that the primary regulatory circuit is repression by more readily bioavailable sulphur (sulphate, cysteine, methionine) (Li et al., 1996; Ohshiro et al., 1996b), a result which is consistent with the hypothesis that this pathway serves a sulphurscavenging function.

A number of other DBT-desulphurizing rhodococci have been reported. These include $R$. erythropolis strains D-1 (Izumi et al., 1994), H-2 (Ohshiro et al., 1996a) and N-36 (Wang \& Krawiek, 1996; Wang et al., 1996); Rhodococcus sp. strain SY1 (Omori et al., 1995), first reported as Corynebacterium sp. strain SY1 (Omori et al., 1992); strains UM3 and UM9, provisionally identified as rhodococci (Purdy et al., 1993); Rhodococcus sp. strains B1, If, Ig and Ih (Denis-Larose et al., 1997); and strain ECRD-1, which was initially classified as a strain of Arthrobacter (Lee et al., 1995) and is now reclassified as R. erythropolis strain ATCC 55310 (Denis-Larose et al., 1997).

Other DBT-desulphurizing isolates have been classified as Agrobacterium strain MC501 (Constanti et al., 1996), Mycobacterium strain G3 (Nekodzuka et al., 1997) and Paenibacillus strain A11-2 (Konishi et al., 1997). All of these isolates are reported to desulphurize DBT to HBP, but are otherwise poorly characterized.

The rhodococcal DBT-desulphurization enzymes have a fairly relaxed specificity for members of the DBT family and will desulphurize alkyl- or aryl-substituted DBT derivatives to the corresponding monophenol (Lee et al., 1995; Ohshiro et al., 1996a). However, these isolates seem to be incapable of desulphurizing benzothiophene (BTH). Thus strains IGTS8, ECRD-1 and N1-36 are unable to grow in mineral salts media containing BTH as sole source of sulphur (Kayser et al., 1993; Lee et al., 1995; Wang \& Krawiec, 1996). This result has important implications for the development of a microbial process for the desulphurization of crude oil and its distillates, since the aromatic organic sulphur fraction is comprised of both dibenzothiophenes and benzothiophenes. There- fore a screening programme was carried out with the objective of isolating micro-organisms capable of desulphurizing BTH.

This paper describes the isolation and characterization of Gordona sp. strain 213E (NCIMB 40816), which is capable of desulphurizing BTH and is therefore complementary in its role in fuel desulphurization to that of DBT-desulphurizing isolates. The basic growth properties of strain $213 \mathrm{E}$ on BTH are described; characterization of BTH metabolites, obtained by ethyl acetate extraction of culture media, is presented and a pathway for BTH desulphurization is proposed. Experiments were carried out to confirm that strain IGTS8 was incapable of desulphurizing BTH (Kayser et al., 1993) and it was also found that strain $213 \mathrm{E}$ was incapable of desulphurizing DBT. On this basis it is postulated that strains IGTS8 and 213E respectively express DBT- and $\mathrm{BTH}$-specific desulphurizing enzyme systems.

\section{METHODS}

Materials. The buffers HEPES and HEPPS and Gibb's reagent (2,6-dichloroquinone 4-chloroimide) were obtained from Sigma. DBT $(99+\%)$, DBTO $_{2}(97 \%)$, HBP (sold as 2phenylphenol; $99+\%)$, BTH (sold as thianaphthene; $99 \%$ ) and BFU (sold as 2,3-benzofuran, 99\%) were obtained from Aldrich. Bacto and Noble agar were obtained from Difco. Glucose, fructose and glycerol were obtained from Merck.

Bacteria. Rhodococcus sp. strain IGTS8 (ATCC 53968) was obtained from J. Kilbane (Institute of Gas Technology, Chicago, IL, USA). Gordona sp. strain 213E (NCIMB 40816) was isolated in this work (see below).

Culture medium. Rhodococcus medium (RM) has the following composition (per litre): $\mathrm{Na}_{2} \mathrm{HPO}_{4}, 4.33 \mathrm{~g} ; \mathrm{KH}_{2} \mathrm{PO}_{4}$, $2.65 \mathrm{~g} ; \mathrm{NH}_{4} \mathrm{Cl}, 2 \mathrm{~g} ; \mathrm{MgCl}_{2} \cdot 6 \mathrm{H}_{2} \mathrm{O}, 0.64 \mathrm{~g}$; nitrilotriacetic acid, $0.1 \mathrm{~g} ; \mathrm{CaCl}_{2} .2 \mathrm{H}_{2} \mathrm{O}, 33 \mathrm{mg} ; \mathrm{ZnCl}_{2}, 2.6 \mathrm{mg} ; \mathrm{FeCl}_{2} .4 \mathrm{H}_{2} \mathrm{O}$, $2.6 \mathrm{mg}$; EDTA, $1.25 \mathrm{mg} ; \mathrm{MnCl}_{2} .4 \mathrm{H}_{2} \mathrm{O}, 1.0 \mathrm{mg}$; $\mathrm{CuCl}_{2} .2 \mathrm{H}_{2} \mathrm{O}$, $0.15 \mathrm{mg} ; \mathrm{Co}\left(\mathrm{NO}_{3}\right)_{2} \cdot 6 \mathrm{H}_{2} \mathrm{O}, 0.125 \mathrm{mg} ; \mathrm{Na}_{2} \mathrm{~B}_{4} \mathrm{O}_{7} \cdot 10 \mathrm{H}_{2} \mathrm{O}$, $0.10 \mathrm{mg} ;\left(\mathrm{NH}_{4}\right)_{6} \mathrm{Mo}_{7} \mathrm{O}_{24} \cdot 4 \mathrm{H}_{2} \mathrm{O}, 0.09 \mathrm{mg}$; final pH 7.2 without titration. After autoclaving $\left(121^{\circ} \mathrm{C}, 20 \mathrm{~min}\right)$, filter-sterilized aqueous glycerol or fructose was added to a final concentration of $10 \mathrm{~g} \mathrm{l}^{-1}$, to give, respectively, glycerol Rhodococcus medium (glyRM) or fructose Rhodococcus medium (fruRM). The sulphur source was added to a final concentration of $200 \mu \mathrm{M}$. DBT or BTH was added from stock solutions in acetone $(40 \mathrm{mM})$; sodium sulphate was added from a filter-sterilized stock solution in water $(40 \mathrm{mM})$.

Strain IGTS8 was maintained at $30^{\circ} \mathrm{C}$ on fruRM agar plates (Difco Noble agar, $20 \mathrm{~g} \mathrm{l}^{-1}$ ) containing either DBT or sulphate, and strain $213 \mathrm{E}$ was maintained on fruRM agar containing either BTH or sulphate. Both strains were subcultured each week.

Isolation of Gordona sp. strain 213E. Gordona sp. strain 213E was isolated by enrichment culture in glyRM $+\mathrm{BTH}$ using as an inoculum a soil sample taken from the vicinity of an oil shale spoil heap located at a disused mine located at West Calder (West Lothian, Scotland). One hundred millilitres of glyRM + BTH in a $250 \mathrm{ml}$ Erlenmeyer flask was inoculated with $20 \mathrm{~g}$ soil and incubated in an orbital shaker (120 r.p.m., $30^{\circ} \mathrm{C}$ ) for $14 \mathrm{~d}$. This culture was enriched for BTH-degrading organisms by fivefold serial transfer of $1 \mathrm{ml}$ into $50 \mathrm{ml}$ glyRM $+\mathrm{BTH}$, in a $100 \mathrm{ml}$ Erlenmeyer flask, with $14 \mathrm{~d}$ incubation at $30^{\circ} \mathrm{C}$. A $100 \mu \mathrm{l}$ aliquot from the fifth transfer 
was serially diluted onto glyRM $+\mathrm{BTH}$ plates $(15 \mathrm{~g}$ Noble Agar $\mathrm{I}^{-1}$ ) and these were incubated at $30^{\circ} \mathrm{C}$ until average colony sizes of $5 \mathrm{~mm}$ were obtained. Representative single colonies were used to inoculate $20 \mathrm{ml}$ aliquots of glyRM $+\mathrm{BTH}$ in $50 \mathrm{ml}$ Erlenmeyer flasks. The flasks were incubated ( 120 r.p.m., $30^{\circ} \mathrm{C}$ ) until $\mathrm{OD}_{600}>9.0$ (about $5 \mathrm{~d}$ ). Only flasks inoculated with colonies designated $213 \mathrm{E}$ and $213 \mathrm{~F}$ yielded this level of growth. Serial dilution and plating out of these cultures onto glyRM $+\mathrm{BTH}$ agar plates gave, after $5 \mathrm{~d}$ incubation, predominantly one organism in each case, as judged by colony morphology and Gram staining. Selected colonies from each plate, grown in glyRM $+B T H$, yielded only one organism by the same criteria. The two isolates were designated as strains $213 \mathrm{E}$ and $213 \mathrm{~F}$ and deposited as NCIMB 40816 and 40817, respectively. In terms of BTH-desulphurizing activity, strain $213 \mathrm{~F}$ was identical to strain $213 \mathrm{E}$ and will not be discussed further.

Growth studies. Fifty millilitres of medium, containing the appropriate sulphur source, in a $100 \mathrm{ml}$ Erlenmeyer flask was inoculated with cells from a single colony of strain $213 \mathrm{E}$ (from a fruRM + BTH agar plate) or of strain IGTS8 (from a fruRM + DBT agar plate). The flasks were incubated in an orbital shaker $\left(120\right.$ r.p.m., $\left.30^{\circ} \mathrm{C}\right)$. At intervals $3 \mathrm{ml}$ of culture was withdrawn for measurement of biomass $\left(\mathrm{OD}_{600}\right)$ and estimation of accumulated phenolic compounds by Gibb's assay, as follows. A $1.5 \mathrm{ml}$ sample of culture was put into an Eppendorf tube, centrifuged (12000 r.p.m., $5 \mathrm{~min}$ ) to pellet cells and the supernatant frozen $\left(-20^{\circ} \mathrm{C}\right)$ until the end of the experiment. Then $1.0 \mathrm{ml}$ was transferred to a $1 \mathrm{ml}$ disposable spectrophotometer cuvette $(1 \mathrm{~cm}$ pathlength) and $10 \mu \mathrm{l}$ Gibbs reagent ( $10 \mathrm{mM}$ in acetone) was added. A blank solution (fruRM $+10 \mu \mathrm{l}$ Gibbs reagent) was also prepared. After overnight incubation at $30^{\circ} \mathrm{C}$ the $A_{610}$ was measured, with dilution if necessary to keep $A_{610}$ below $1 \cdot 0 . A_{610}$ was converted to $[\mathrm{HBP}]$ using a standard curve, prepared under the same conditions, with authentic HBP in the range $0-30 \mu \mathrm{M}$. HPEal is not commercially available and it was not possible to construct a standard curve. However it was noted that fruRM + BTH recovered following growth of strain 213E well into stationary phase $(150 \mathrm{~h})$ always gave $A_{610}=0.75$, approx., on addition of Gibb's reagent followed by overnight incubation at $30^{\circ} \mathrm{C}$. Therefore, with the assumption that $[\mathrm{HPEal}]=200 \mu \mathrm{M}$ (i.e. complete conversion of BTH to HPEal), $\varepsilon_{610}=3800 \mathrm{M}^{-1} \mathrm{~cm}^{-1}$ for the Gibb's-HPEal adduct. Therefore [HPEal] was estimated from the expression [HPEal] $/ \mu \mathrm{M}=10^{6} A_{610} / 3800$ (where $A_{610}$ was measured in a $1 \mathrm{~cm}$ pathlength cell).

Isolation of organic metabolites and GC-MS analysis. Cultures of strain IGTS8 or strain 213E were grown in fruRM to the end of the exponential phase $(60 \mathrm{~h})$. Cells were removed by centrifugation at 3000 r.p.m. $(1600 \mathrm{~g})$ for $30 \mathrm{~min}$. The supernatant was titrated to $\mathrm{pH} 1$ with $50 \% \mathrm{HCl}$ and extracted three times with an equal volume of ethyl acetate. The extracts were pooled, dried by stirring for $1 \mathrm{~h}$ with anhydrous $\mathrm{MgSO}_{4}$ $\left(100 \mathrm{~g} \mathrm{l}^{-1}\right)$, and the ethyl acetate removed by rotary evaporation. The solids were redissolved in $3.0 \mathrm{ml}$ ethyl acetate. GC-MS analysis of metabolites was carried out using a Hewlett Packard 5890 series II gas chromatograph coupled to a 5972 series mass-selective detector. The gas chromatograph was fitted with a Hewlett Packard capillary column HP-5MS, length $30 \mathrm{~m}$. The carrier gas was helium. Run conditions were as follows: start temperature $40^{\circ} \mathrm{C}$ held for $2 \mathrm{~min}$, followed by $10^{\circ} \mathrm{C} \mathrm{min}^{-1}$ ramp rate to a final temperature of $240^{\circ} \mathrm{C}$. Where possible, structural assignments were confirmed using the on-line G1035A Wiley PBM library (John Wiley \& Sons, New York .
Studies on the metabolism of DBT and BTH by pre-grown cells. DBT-desulphurization-active cells of strain IGTS8 were grown in fruRM+DBT, and BTH-desulphurization-active cells of strain $213 \mathrm{E}$ were grown in fruRM $+\mathrm{BTH}$, to the end of the exponential phase $(60 \mathrm{~h})$. The cells were recovered by centrifugation at 4200 r.p.m. $(1700 \mathrm{~g})$ for $15 \mathrm{~min}$, washed twice with and finally resuspended in, $50 \mathrm{mM}$ HEPPS buffer, $\mathrm{pH} \mathrm{8}$, to $\mathrm{OD}_{600} 10$. Each suspension was divided into two aliquots, and to each of these either BTH or DBT was added, from $40 \mathrm{mM}$ stocks in acetone, to a final concentration of $200 \mu \mathrm{M}$. After overnight incubation at $30^{\circ} \mathrm{C}$ on an orbital shaker ( 120 r.p.m.) the cells were removed by centrifugation and the supernatants were extracted with ethyl acetate for GC-MS analysis.

\section{RESULTS}

\section{Gordona sp. strain 213E grows in a mineral salts medium containing fructose as a source of carbon and energy and BTH as the sole source of sulphur}

When grown on fruRM + BTH Noble Agar plates for $3 \mathrm{~d}$, colonies of strain $213 \mathrm{E}$ were pink, mucoid, with entire margins and umbonate elevation, and stained as slender Gram-positive rods of irregular length. Strain $213 \mathrm{E}$ was obligately aerobic, non-motile, partially acidfast, catalase-positive and oxidase-positive. Glucose,
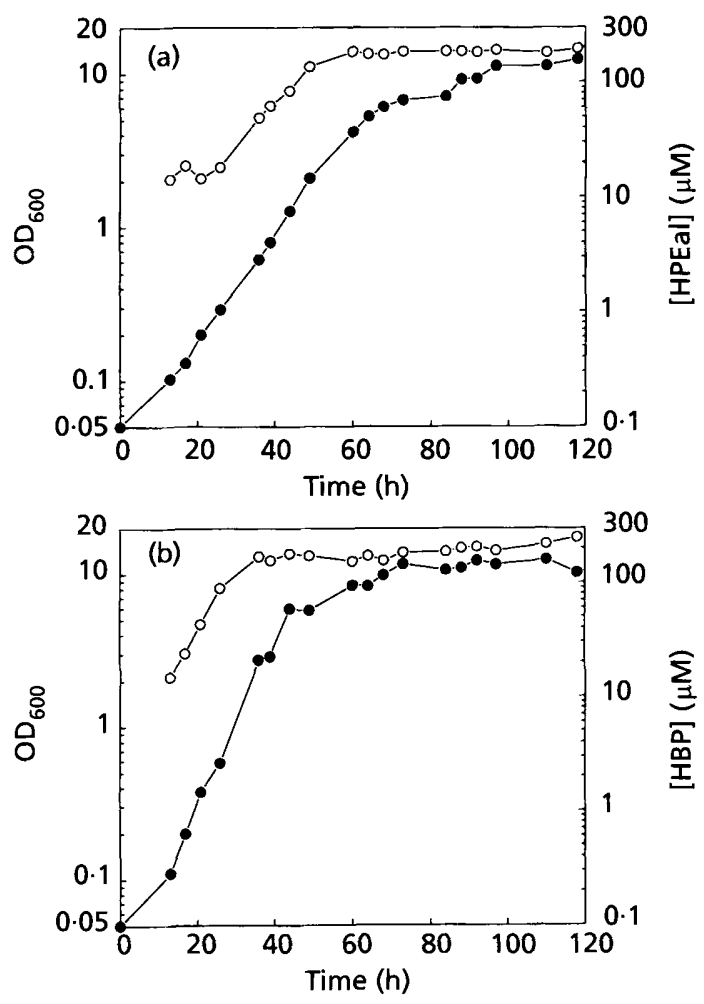

Fig. 1. Growth curves for desulphurizing bacterial strains. (a) Gordona sp. strain $213 \mathrm{E}$ grown in fruRM + BTH; (b) Rhodococcus sp. strain IGTS8 grown in fruRM + DBT. C, Cell density measured as $\mathrm{OD}_{600}(1 \mathrm{~cm}$ pathlength cuvette); $O$, concentration of accumulated HPEal or HBP, as determined by Gibb's assay. 
mannitol, pyruvate, citrate and glycerol could be substituted for fructose in this medium. 16S rRNA analysis indicates that strain 213E belongs to the genus Gordona (S. Kim, C. Oldfield \& M. Goodfellow, unpublished).

Strain $213 \mathrm{E}$ grew in fruRM $+\mathrm{BTH}$ at $30^{\circ} \mathrm{C}$ with a mean doubling time of $9 \mathrm{~h}$ and a phenolic compound accumulated in the medium, as indicated by the production of a blue colour on addition of Gibb's reagent. The phenolic compound was identified as HPEal by GC-MS analysis (see below). Complete desulphurization correlates roughly with the end of exponential growth in this sulphur-limited medium (Fig. 1a). This behaviour can be compared (Fig. 1b) with that of strain IGTS8, which grew in fruRM + DBT with a doubling time of $7 \mathrm{~h}$ and HBP (identity confirmed by GC-MS analysis; data not shown) accumulated as expected (Kayser et al., 1993; Oldfield $e$ t al., 1997).

Strains 213E and IGTS8 grew in fruRM + sulphate with doubling times of $3 \mathrm{~h}$ and $4 \mathrm{~h}$, respectively. Therefore growth with an organosulphur source was rather slower than with a more readily bioavailable inorganic source of sulphur. No blue colour was produced following addition of Gibb's reagent to culture medium supernatant. When strain $213 \mathrm{E}$ was grown in fruRM containing $200 \mu \mathrm{M}$ of each of sulphate and BTH, no blue colour was produced on addition of Gibbs reagent to the medium, indicating that BTH desulphurization did not occur (data not shown). Therefore it was concluded that BTH was not metabolized by strain 213E in the presence of sulphate.

\section{Characterization of metabolites extracted from culture supernatants of strain 213E grown in fruRM + BTH enables prediction of a metabolic pathway for BTH desulphurization}

When strain 213E was grown in fruRM + BTH to midor end-exponential phase, GC analysis of ethyl acetate extracts of the culture medium revealed a total of seven peaks $(\mathrm{a})-(\mathrm{g})$ which were absent from extracts of cultures grown on fruRM+sulphate (Fig. 2). The structure of each compound was deduced by MS (Fig. $3 a-g)$ as follows:

Peaks (a) and (b). Benzofuran (BFU) and benzothiophene (BTH), respectively, assigned on the basis of GC retention times (Fig. 2) and mass spectra (Fig. 3a, b) identical to those of commercially available standards.

Peak (c). 2-(2'-Hydroxyphenyl)ethan-1-al (HPEal); molecular ion peak at $m / e=136$; high-abundance fragment-ion at $m / e=107$ corresponds to loss of $\mathrm{CHO}$ (aldehyde moiety) from the molecular ion. Fragmentions at $m / e=91,90$ and 89 correspond to loss of phenolic oxygen plus 0,1 or $2 \mathrm{H}$, respectively from the $m / e=107$ fragment-ion, and the fragment-ion at $m / e$ $=77$ is $\mathrm{C}_{6} \mathrm{H}_{5}^{+}$(Fig. 3c). Actually HPEal could be expected to exist as a mixture of HPEal and cis- and trans-2-(2'-hydroxyphenyl)ethen-1-ol (cis- and transHPEol), due to keto-enol tautomerization. For this particular interconversion no value for the equilibrium constant, $K_{\mathrm{eq}}=([$ cis-enol $]+[$ trans-enol $]) /[$ keto $]$ was

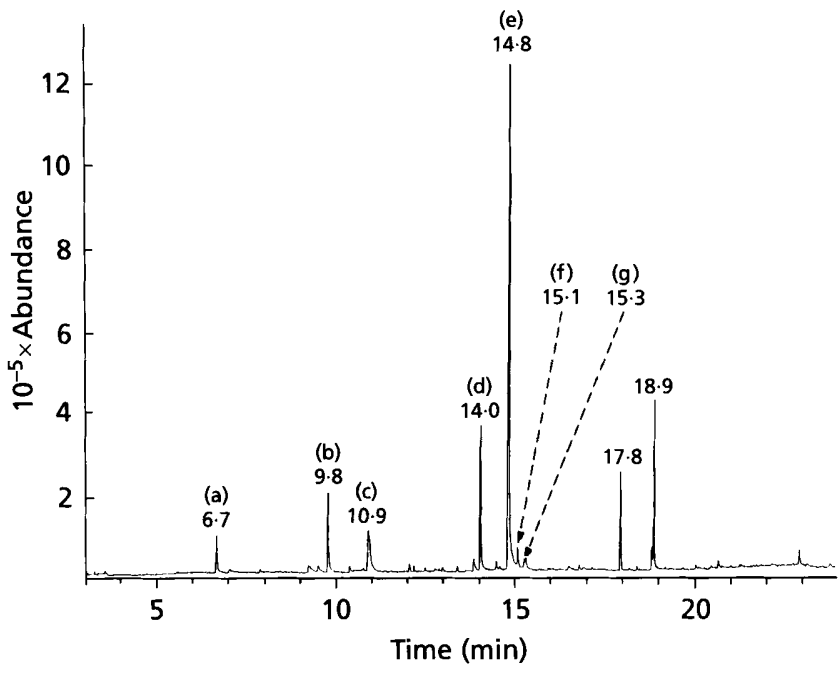

Fig. 2. Gas chromatogram of an ethyl acetate extract of the culture medium of strain $213 \mathrm{E}$ containing BTH $(200 \mu \mathrm{M})$ as sole sulphur source. The culture was grown in $50 \mathrm{ml}$ fruRM + BTH in a $100 \mathrm{ml}$ Erlenmyer flask, incubated in an orbital shaker $(120$ r.p.m.; $30^{\circ} \mathrm{C}$ ) to the end of the exponential phase (approx. $60 \mathrm{~h}$ ) and extracted with ethyl acetate as described in Methods.

found in the literature. However for the closely related couple, 2-phenylethen-1-ol $\leftrightarrow 2$-phenylethan-1-al, $K_{\mathrm{eq}}$ $=1.3 \times 10^{-3}$ in aqueous solution at neutral $\mathrm{pH}$ and $20{ }^{\circ} \mathrm{C}$ (Chiang et al., 1989). Therefore, this compound can be regarded for practical purposes as HPEal.

Peak (d). Benzo[ $e][1,2]$ oxathiin $S$-oxide (BcOTO); molecular ion peak at $m / e=166$ and high-abundance fragment-ion at $m / e=118$ corresponding to loss of $\mathrm{S}=\mathrm{O}$ (Fig. 3d). This is the common mode of sultine fragmentation under electron impact (Bowie et al., 1966; Fields \& Meyerson, 1966). (See Fig. 4.) BcOTO is the condensed 'sultine' form of the alkenyl sulphinate, $(Z)$ 2-(2'-hydroxyphenyl)ethen 1-sulphinate ( $\left.\mathrm{HPESi}^{-}\right)$. The situation here is analogous to the case in DBT desulphurization, where $\mathrm{HBPSi}^{-}$is actually isolated as the sultine, dibenz $[c, e][1,2]$ oxathiin $S$-oxide (BPSi; Oldfield et al., 1997). Sultines are stable in aqueous solution only at $\mathrm{pH}<2$ and are formed under the conditions of the ethyl acetate extraction procedure. At physiologically relevant (neutral) $\mathrm{pH}$, these compounds exist exclusively as the sulphinate (Hanson \& Kemp, 1981).

Peak (e). Benzothiophene $S$-oxide (BTHO); weak molecular ion peak at $m / e=150$; the high-abundance fragment-ion at $m / e=134$ is $\mathrm{BTH}^{+}$derived by loss of the sulphinyl oxygen (Fig. 3e). The low abundance of molecular ion, due to the lability of the $S=0$ double bond, is typical of aromatic sulphoxides.

Peak (f). Benzothiophene $S, S$-dioxide $\left(\mathrm{BTHO}_{2}\right) ;$ molecular ion peak at $m / e=166$; fragment-ion peaks at $m / e=150$ and $m / e=134$, consistent with the loss of $\mathrm{O}$ and $2 \mathrm{O}$, respectively, from the molecular ion peak (Fig. $3 f)$. The high-abundance $m / e=118$ and $m / e=137$ 

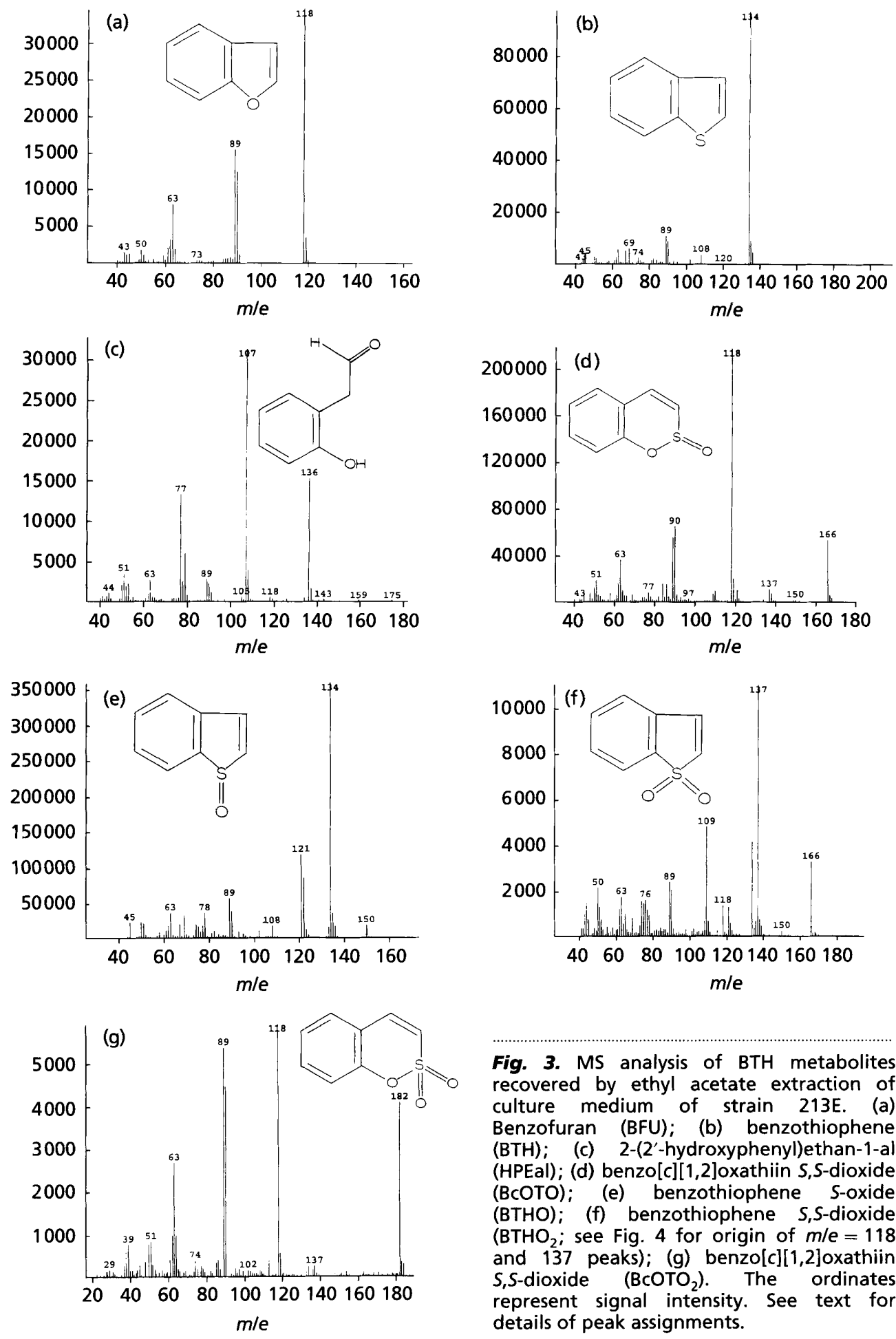

Fig. 3. MS analysis of BTH metabolites recovered by ethyl acetate extraction of culture medium of strain 213E. (a) Benzofuran (BFU); (b) benzothiophene (BTH); (c) 2-(2'-hydroxyphenyl)ethan-1-al (HPEal); (d) benzo[c][1,2]oxathiin S,S-dioxide (BCOTO); (e) benzothiophene S-oxide (BTHO); ( $f$ ) benzothiophene S,S-dioxide $\left(\mathrm{BTHO}_{2}\right.$; see Fig. 4 for origin of $m / e=118$ and 137 peaks); (g) benzo[c][1,2]oxathiin S,S-dioxide $\left(\mathrm{BCOTO}_{2}\right)$. The ordinates represent signal intensity. See text for details of peak assignments.

peaks are also consistent with the identity of this species as $\mathrm{BTHO}_{2}$, given that this molecule may convert to either of two isomeric sultine species, under electronimpact, prior to fragmentation (Bowie et al., 1966; Fields \& Meyerson, 1966; Olson et al., 1993). As shown in Fig. 4 , the $m / e=118$ peak arises from isomerization of $\mathrm{BTHO}_{2}$ to benzo[c][1,2] oxathiin $S$-oxide (BcOTO) followed by loss of $\mathrm{S}=\mathrm{O}$ (cf. Fig. 3d), and isomerization of $\mathrm{BTHO}_{2}$ to benzo[e][1,2] oxathiin $S$-oxide (BeOTO) followed by loss of $\mathrm{CHO}$ is responsible for the $m / e=$ 137 peak.

Peak (g). Benzo[c][1,2]oxathiin S,S-dioxide $\left(\mathrm{BcOTO}_{2}\right)$; molecular ion peak at $m / e=182$ and abundant fragment ion peak at $m / e=118$ corresponding to loss of $\mathrm{SO}_{2}$ (Fig. 3g). This is a common mode of sultone fragmentation under electron impact.

Other peaks in Fig. 2 correspond to compounds which 


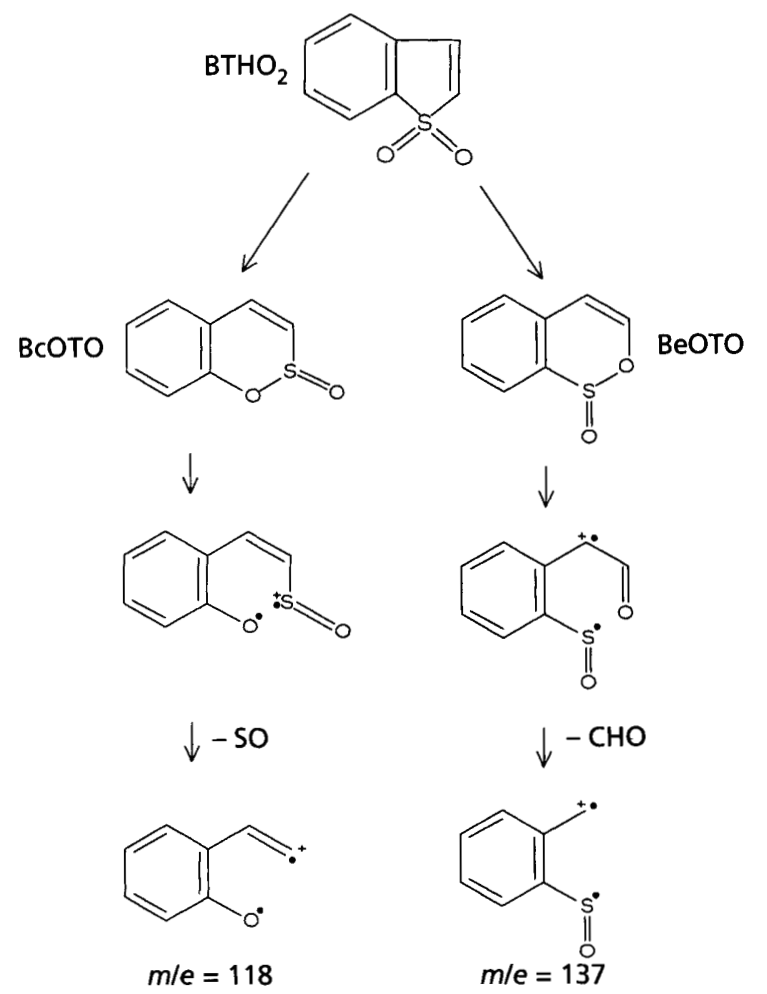

Fig. 4. Fragmentation behaviour of $\mathrm{BTHO}_{2}$ under electronimpact. The mass spectrum in Fig. $3(f)$ was consistent with the identity of the molecule as $\mathrm{BTHO}_{2}$ on the basis that this molecule can isomerize either to ВсOTO or to ВеOTO, prior to fragmentation, so that the resulting mass spectrum contains fragment-ions characteristic of both of these molecules, in addition to those characteristic of $\mathrm{BTHO}_{2}$ itself. The left-hand route indicates the fragmentation pattern of BCOTO, characterized by the strong $m / e=118$ fragment-ion due to loss of $S=0$ and the right-hand route indicates the fragmentation pattern of BeOTO, characterized by the strong $\mathrm{m} / \mathrm{e}=137$ fragment-ion due to loss of $\mathrm{CHO}$.

cannot be BTH metabolites. By reference to library spectra, the peaks at 17.8 and 18.9 min were assigned respectively as a benzene 1,2-dicarboxylate diester and as hexadecanoic acid. These peaks also appear in ethyl acetate extracts of cells grown on fruRM + sulphate (data not shown).

Based on the identities of these metabolites, it was possible to propose a metabolic pathway for BTH desulphurization by strain 213E (Fig. 5a). The proposed sequence is: $\mathrm{BTH} \rightarrow \mathrm{BTHO} \rightarrow \mathrm{BTHO}_{2}$ (activation of sulphur to facilitate thiophene ring-opening); $\mathrm{BTHO}_{2} \rightarrow \mathrm{HPESi}^{-}$(thiophene ring-opening), and finally $\mathrm{HPESi}^{-} \rightarrow$ HPEal (desulphination). As already indicated, $\mathrm{HPESi}^{-}$is the stable form of $\mathrm{BcOTO}$ in aqueous solution at neutral $\mathrm{pH}$. It was therefore concluded that HPEal is the final organic product of BTH desulphurization and that this is the Gibb's-reagentreactive phenolic compound which accumulates in culture media during growth of strain $213 \mathrm{E}$ on BTH (Fig. 1a). The presence of BFU was attributed to partial (a)

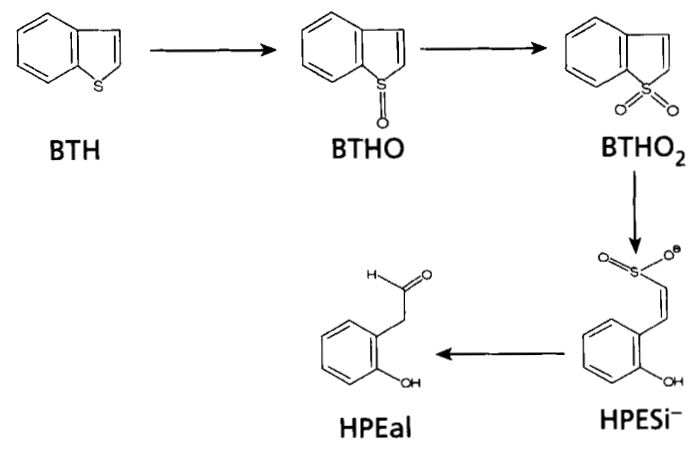

(b)

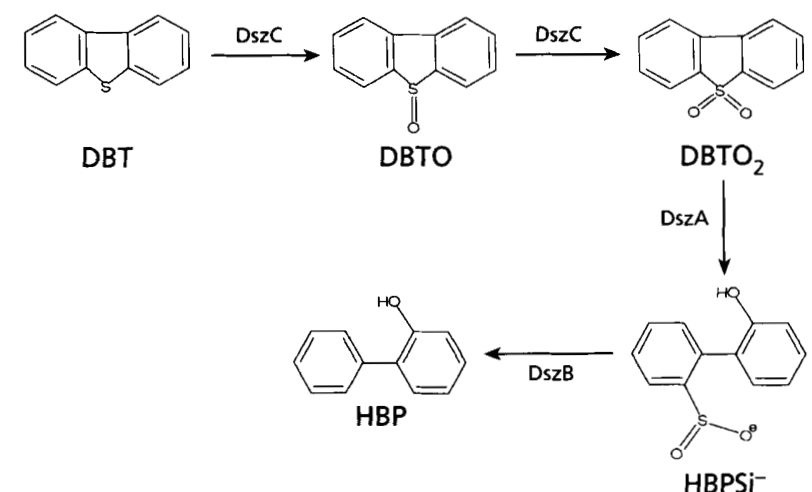

Fig. 5. Comparison of the proposed BTH desulphurization pathway with the DBT desulphurization pathway. (a) Proposed BTH desulphurization pathway for Gordona sp. strain 213E. (b) DBT desulphurization pathway of Rhodococcus sp. strain IGTS8 (Oldfield et al., 1997).

dehydration of HPEal during the ethyl acetate extraction procedure (Joule et al., 1995).

$\mathrm{BcOTO}_{2}$ was not included in the pathway shown in Fig. 5 (a). It was concluded that this was a dead-end metabolite formed by oxidation of BcOTO: a sidereaction which is irrelevant for the main desulphurization pathway.

\section{Strain 213E does not desulphurize DBT and strain IGTS8 does not desulphurize BTH}

Strain 213E did not grow in fruRM + DBT and it was concluded that this isolate was unable to desulphurize DBT. Similarly, strain IGTS8 did not grow in fruRM $+\mathrm{BTH}$ and it was concluded that the organism was unable to desulphurize BTH (this latter result confirms an earlier observation; Kayser et al., 1993). When DBT-desulphurization-competent cells of strain IGTS8 were incubated overnight in $50 \mathrm{mM}$ HEPPS buffer, $\mathrm{pH} 8$, containing $\mathrm{BTH}$, ethyl acetate extraction yielded none of the expected BTH metabolites, BTHO, $\mathrm{BTHO}_{2}, \mathrm{BcOTO}$ or HPEal. Similarly, when BTHdesulphurization-competent cells of strain 213E were incubated overnight in $50 \mathrm{mM}$ HEPPS buffer, $\mathrm{pH} 8$, containing DBT, ethyl acetate extraction yielded none 
of the expected DBT metabolites, DBTO, $\mathrm{DBTO}_{2}$, BPSi (the condensed sultine form of $\mathrm{HBPSi}^{-}$) or HBP. This kind of experiment was carried out several times and the result was reproducible. Therefore it was concluded that strains IGTS8 and 213E are respectively unable to metabolize BTH and DBT.

\section{DISCUSSION}

\section{Gordona sp. strain 213E is a novel BTH-desulphurizing bacterium}

This is the first report of a bacterium which is able to desulphurize BTH. Gordona sp. strain 213E grew in a mineral salts medium with fructose as a source of carbon and energy and with BTH as the sole sulphur source. During growth a phenolic compound, identified as HPEal, accumulated and it was concluded that this was the unused carbon skeleton of BTH.

No phenolic compounds were produced by cultures of strain 213E grown in fruRM + sulphate, or in fruRM containing $200 \mu \mathrm{M}$ each of BTH and sulphate, as determined by Gibb's assay. It was concluded from the latter result that expression of the BTH-desulphurizing enzymes was repressed by sulphate, a source of more readily bioavailable sulphur, and therefore that this is a sulphur-scavenging pathway. There is a parallel here with Rhodococcus sp. strain IGTS8, which is able to scavenge sulphur by desulphurizing DBT using a pathway which does not degrade the carbon skeleton (Fig. $5 \mathrm{~b}$ ), and which is also repressed by sulphate ( $\mathrm{Li}$ et al., 1996).

\section{The existence of separate BTH- and DBT-specific desulphurization pathways is consistent with predicted differences in the chemistry of the two substrates}

Using metabolites (a)-(f) (Figs 2 and 3) a pathway for BTH desulphurization was constructed (Fig. 5a). This pathway can be compared with that for DBT desulphurization by Rhodococcus sp. strain IGTS8 (Fig. $5 b)$. Thus the first step, $\mathrm{BTH} \rightarrow \mathrm{BTHO} \rightarrow \mathrm{BTHO}_{2}$, mirrors the sequence $\mathrm{DBT} \rightarrow \mathrm{DBTO} \rightarrow \mathrm{DBTO}_{2}$ and it was concluded that strain $213 \mathrm{E}$ must produce an $S$ oxygenase equivalent to DszC.

The following step, $\mathrm{BTHO}_{2} \rightarrow \mathrm{HPESi}^{-}$, the thiophene ring-opening reaction triggered by hydroxylation of the aryl C-S carbon, likewise mirrors the step $\mathrm{DBTO}_{2} \rightarrow$ HBPSi $^{-}$. The presence of BcOTO (the condensed form of $\mathrm{HPESi}^{-}$present in ethyl acetate extracts) was taken as direct evidence for ring-opening by cleavage of the aryl $\mathrm{C}-\mathrm{S}$ bond, rather than of the alkenyl $\mathrm{C}-\mathrm{S}$ bond. In principle, ring opening could also proceed by way of cleavage of the alkenyl $\mathrm{C}-\mathrm{S}$ bond. However, if this were the case, the isomeric BeOTO (the sultine of $2-\left[(Z)-2^{\prime}-\right.$ hydroxyethen]benzene 1-sulphinate) should be expected instead of, or in addition to, BcOTO. BcOTO and $\mathrm{BeOTO}$ are distinguishable by their mass spectra (Fig. 4). BeOTO was never found, despite detailed exam- ination of numerous gas chromatograms, and therefore it was concluded that opening of the thiophene ring of $\mathrm{BTHO}_{2}$ occurs exclusively by cleavage of the aryl C-S bond. On this basis it was also concluded that strain $213 \mathrm{E}$ must produce an enzyme which in this respect is identical to DszA (Fig. 5b).

The final step in the proposed pathway is the desulphination of $\mathrm{HPESi}^{-}$to HPEal. In the strain IGTS8 DBT-desulphurization pathway, desulphination occurs by DszB-catalysed hydrolysis: $\mathrm{HBPSi}^{-}+\mathrm{H}_{2} \mathrm{O} \rightarrow$ $\mathrm{HBP}+$ sulphite (Fig. 5b). Although aryl sulphinates, such as HBPSi $^{-}$, can be desulphinated in this way the alkenylsulphinate, $\mathrm{HPESi}^{-}$, cannot and therefore strain $213 \mathrm{E}$ is not expected to produce an enzyme equivalent to DszB. It is proposed instead that $\mathrm{HPESi}^{-}$desulphination occurs by oxygenase-catalysed hydroxylation of the C-S carbon, which would permit the expulsion of sulphite. The immediate product of this reaction would be an enol (either $c i s$ - or trans-HPEol, depending on the precise enzymic mechanism), which would tautomerize to HPEal on release from the active site. As already indicated the keto-enol equilibrium is expected to lie strongly in favour of HPEal. The sulphur-containing product of BTH-desulphurization has not yet been identified and these studies await the availability of $\left[{ }^{35} \mathrm{~S}\right] \mathrm{BTH}$.

\section{Differences in chemistry of DBT and BTH desulphurization cannot be the only explanation for the lack of cross-specificity between the two pathways}

As already discussed, the DBT- and BTHdesulphurization mechanisms differ crucially in the nature of the sulphinic acid generated following thiophene ring-opening. On this basis alone it is reasonable to expect that DBT and BTH desulphurization would require separate pathways. However, the earlier steps, viz. S-oxygenation of the substrate to give the dioxide, followed by opening of the thiophene ring by hydroxylation of an aromatic $\mathrm{C}-\mathrm{S}$ carbon, are common (Fig. 5) to both pathways and on this basis it was reasonable to expect desulphurization of BTH by strain IGTS8 to proceed as far as HPESi ${ }^{-}$. Nevertheless, when pre-grown, DBT-desulphurization-competent, strain IGTS8 was challenged with BTH there was no production of $\mathrm{BTHO}, \mathrm{BTHO}_{2}$ or $\mathrm{HPESi}^{-}$and it was concluded that $\mathrm{BTH}$ was not a substrate for the entrypoint $S$-oxygenase (DszC). On the same basis, whilst there was no reason to expect the strain 213E $\mathrm{HPESi}^{-}$desulphinating enzyme to desulphurize $\mathrm{HBPSi}^{-}$, it was reasonable to hypothesize that strain $213 \mathrm{E}$ would metabolize DBT at least as far as HBPSi ${ }^{-}$. When BTHdesulphurization-competent strain $213 \mathrm{E}$ was challenged with DBT, however, there was no production of DBTO, $\mathrm{DBTO}_{2}$ or $\mathrm{HBPSi}^{-}$and it was concluded that DBT was not a substrate for the strain 213E equivalent of DszC.

Therefore it was concluded that the mutual exclusivity of the two pathways arises not only from the need for different chemistry at the final desulphination step, but 
also from a correspondingly narrow substrate specificity of the entry-point $S$-oxygenase.

\section{Conclusions}

Gordona sp. strain 213E possesses a novel BTHdesulphurizing capability. From the point of view of development of fossil fuel desulphurization technology, this activity is complementary to that of DBTdesulphurizing isolates such as Rbodococcus sp. strain IGTS8. Fossil fuels contain both benzothiophenes and dibenzothiophenes and it is therefore necessary to target both families of compounds in order to achieve maximal desulphurization. The existence of separate DBT- and BTH-specific pathways is consistent with the need for different kinds of chemistry to carry out the final, desulphinating step; however, this cannot be the whole story, since BTH was not sulphoxidized by strain IGTS8 and DBT was not sulphoxidized by strain 213E, despite the fact that there is common chemistry at this initial stage (compare Fig. 5a and b). Therefore the enzyme responsible, DszC, and its equivalent in strain 213E, seem to possess specificities which are complementary to those of the corresponding desulphinating enzymes. Confirmation of this observation and its understanding in terms of the substrate specificity of the purified enzymes is highly desirable and is being pursued in this laboratory.

Both the DBT- and BTH-specific pathways undoubtedly perform a sulphur-scavenging role for the cell. The extent to which these organisms rely on these pathways in their natural environment is not yet known and it would be interesting to determine the in situ expression levels of these enzymes. Sulphur-scavenging pathways have been characterized in other organisms, including Pseudomonas aeruginosa (arylsulphatase degradation pathway; Beil et al., 1995) and Escherichia coli (taurine degradation pathway; van der Ploeg et al., 1998). However, the DBT and BTH desulphurization pathways are unusual in that the carbon skeleton generated in the desulphurization is not mineralized. DBT desulphurization is an energetically expensive process, estimated to require $4 \mathrm{~mol} \mathrm{NADH}$ per mol DBT desulphurized (Oldfield et al., 1997) and this is probably also the case for BTH desulphurization. Therefore it seems unusual that the carbon skeleton is not mineralized in order to recoup the energy invested. This peculiarity is compounded by the fact that mono- and binuclear aromatic catabolic pathways are known in the rhodococci (Asturias et al., 1994; Kosono et al., 1997; Masai et al., 1997). Mineralization of HBP and HPEal would certainly result in the release of sufficient energy to compensate for that consumed in the desulphurization reaction; nevertheless, there are no reports of strains of Rhodococcus sp. or Gordona sp. which are able to both desulphurize DBT (or BTH) and subsequently mineralize the carbon skeleton.

Thus the existence of the desulphurization phenotype raises some interesting questions relevant to the ecology of such organisms, and in particular of the
Rhodococcus-Gordona-Tsukamurella family. For these reasons, as well as for their potential role in fossil fuel desulphurization, these strains are deserving of further study.

\section{Addendum}

Since this article was accepted the isolation of a DBTdesulphurizing strain of Gordona sp. has been reported (Rhee et al., 1998).

\section{REFERENCES}

Asturias, J. A., Eltis, L. D., Prucha, M. \& Timmis, K. M. (1994). Analysis of three 2,3-dihydroxybiphenyl 1,2-dioxygenases found in Rhodococcus globerulus P6. J Biol Chem 269, 7807-7815.

Beil, S., Kehrli, H., James, P., Staudenmann, W., Cook, A. M., Leisinger, T. \& Kertesz, M. A. (1995). Purification and characterisation of the arylsulfatase synthesised by Pseudomonas aeruginosa PAO during growth in sulfate-free medium and cloning of the arylsulfatase gene (atsA). Eur J Biochem 229, 385-394.

Bowie, J. H., Williams, D. H., Lawesson, S.-O., Madsen, J. Ø., Nolde, C. \& Schroll, G. (1966). Studies in mass spectrometry. XV. Mass spectra of sulphoxides and sulphones. The formation of $\mathrm{C}-\mathrm{C}$ and $\mathrm{C}-\mathrm{O}$ bonds upon electron impact. Tetrabedron 22, 3515-3525.

Chiang, Y., Kresge, A. J., Walsh, P. A. \& Yin, Y. (1989). Phenylacetaldehyde and its cis- and trans-enols and enolate ions. Determination of the cis: trans ratio under equilibrium and kinetic control. J Chem Soc Chem Commun 869-871.

Constanti, M., Girlat, J. \& Bordons, A. (1996). Degradation and desulfurization of dibenzothiophene sulfone and other sulfur compounds by Agrobacterium MC501 and a mixed culture. Enzyme Microb Technol 19, 214-219.

Denis-Larose, C., Labbe, D., Nergeron, H., Jones, A. M., Greer, C. W., Al-Hawari, J., Grossman, M. J., Sankey, B. M. \& Lau, P. C. K. (1997). Conservation of plasmid-encoded dibenzothiophene desulphurisation genes in several rhodococci. Appl Environ Microbiol 63, 2915-2919.

Denome, S. A., Olson, E. S. \& Young, K. D. (1993). Identification and cloning of genes involved in specific desulphurisation of dibenzothiophene by Rhodococcus sp. strain IGTS8. Appl Environ Microbiol 59, 2837-2843.

Denome, S. A., Oldfield, C., Nash, L. J. \& Young, K. (1994). Characterisation of the desulfurization genes from Rhodococcus sp. strain IGTS8. J Bacteriol 176, 6707-6716.

Fields, E. K. \& Meyerson, S. (1966). Pyrolysis and mass spectrum of dibenzothiophene 5,5-dioxide. J Am Chem Soc 88, 2836-2837.

Gray, K. A., Pogrebinsky, O., Mrashko, G. T., Xi, L., Monticello, D. J. \& Squires, C. H. (1996). Molecular mechanisms of biocatalytic desulphurisation of fossil fuels. Nat Biotechnol 14, 1705-1708.

Hanson, G. \& Kemp, D. S. (1981). Convenient routes to 4,4" functionalised $o$-terphenyls and $2,2^{\prime}$ functionalised biphenyls. J Org Chem 46, 5441-5443.

Izumi, Y., Ohshiro, T., Ogino, H., Hine, Y. \& Shimao, M. (1994). Selective desulfurization of dibenzothiophene by Rhodococcus erythropolis strain D-1. Appl Environ Microbiol 60, 223-226.

Joule, J. A., Mills, K. \& Smith, G. F (1995). Heterocyclic Chemistry, 3rd edn, p. 355. London: Chapman \& Hall.

Kayser, K. J., Bielaga-Jones, B. A., Jackowski, K., Odusan, O. \& Kilbane, J. J. (1993). Utilization of organosulphur compounds by 
axenic and mixed cultures of Rhodococcus rhodochrous strain IGTS8. J Gen Microbiol 139, 3123-3129.

Konishi, J., Ishii, Y., Onaka, T., Okumura, K. \& Suzuki, M. (1997). Thermophilic carbon-sulphur bond targeted biodesulfurisation. Appl Environ Microbiol 63, 3164-3169.

Kosono, S., Maeda, M., Fuji, F., Arai, H. \& Kudo, T. (1997). Three of the seven $b p h C$ genes of Rhodococcus erythropolis TA421, isolated from a termite ecosystem, are located on an indigenous plasmid associated with biphenyl degradation. Appl Environ Microbiol 63, 3283-3285.

Lee, M. K., Senius, J. D. \& Grossman, M. J. (1995). Sulfur-specific microbial desulfurization of sterically hindered analogs of dibenzothiophene. Appl Environ Microbiol 61, 4362-4366.

Lei, B. \& Tu, S.-C. (1996). Gene overexpression, purification and identification of a desulfurization enzyme from Rbodococcus sp. strain IGTS8 as a sulfide/sulfoxide monooxygenase. J Bacteriol 17, 5699-5705.

Li, M. Z., Squires, C. H. \& Childs, J. D. (1996). Genetic analysis of the $d s z$ promoter and associated regulatory regions of Rhodococcus erythropolis IGTS8. J Bacteriol 178, 6409-6418.

Masai, E., Sugiyama, K., Iwashite, N., Shimizu, S., Hauschild, J. E., Hatta, T., Kimbara, K., Yano, K. \& Fukuda, M. (1997). The $b p h D E F$ meta-cleavage pathway genes involved in biphenyl/ polychlorinated biphenyl degradation are located on a linear plasmid and separated from the initial $b p h A C B$ genes in Rhodococcus sp. strain RHA1. Gene 187, 141-149.

Nekodzuka, S., Toshiaki, N., Nakajima-Kambe, T., Nobura, N., Lu, J. \& Nakahara, Y. (1997). Specific desulphurisation of dibenzothiophene by Mycobacterium strain G3 Biocatalysis Biotransformation 15, 21-27.

Ohshiro, T., Hirata, T. \& Izumi, Y. (1996a). Desulfurization of dibenzothiophene derivatives by whole cells of Rhodococcus erythropolis strain H-2. FEMS Microbiol Lett 142, 65-70.

Ohshiro, T., Suzuki, K. \& Izumi, Y. (1996b). Regulation of dibenzothiophene-degrading activity of Rhodococcus erythropolis strain D-1. J Ferment Bioeng 81, 121-124.
Oldfield, C., Pogrebinsky, O., Simmonds, J., Olson, E \& Kulpa, C. F. (1997). Elucidation of the metabolic pathway for dibenzothiophene desulphurisation by Rhodococcus sp. strain IGTS8 (ATCC 53968). Microbiology 143, 2961-2973.

Olson, E. S., Stanley, D. C. \& Gallagher, J. R. (1993). Characterisation of intermediates in the microbial desulfurization of dibenzothiophene. Energy \& Fuels 7, 159-164.

Omori, T., Monna, L., Saiki, Y. \& Kodama, T. (1992). Desulfurization of dibenzothiophene by Corynebacterium sp. strain SY1. Appl Environ Microbiol 58, 911-915.

Omori, T., Saiki, Y., Kasuga, K. \& Kodama, T. (1995). Desulfurization of alkyl and aromatic sulfides and sulfonates by dibenzothiophene desulphurising Rhodococcus sp. strain SY1 Biosci Biotechnol Biochem 59, 1195-1198.

van der Ploeg, J. R., Iwanikca-Nowicka, R., Kertesz, M. A., Leisinger, T. \& Hoyniewicz, M. M. (1998). Involvement of CysB and $\mathrm{Cb} 1$ regulatory proteins in the $\tan A B C D$ operon and other sulphate starvation inducible genes in Escherichia coli. J Bacteriol 179, 7671-7678.

Purdy, R. F., Lepo, J. E. \& Ward, B. (1993). Biodesulphurisation of organic sulphur compounds. Curr Microbiol 27, 219-222.

Rhee, S.-K., Chang, J. H., Chang, Y. K. \& Chang, H. O. (1998). Desulfurization of dibenzothiophene and diesel oils by a newly isolated Gordona strain, CYKS1. Appl Environ Microbiol 64, 2327-2331.

Wang, P. \& Krawiec, S. (1996). Kinetic analyses of desulfurization of dibenzothiophene by Rhodococcus erythropolis in batch and fed-batch cultures Appl Environ Microbiol 62, 3066-3068.

Wang, P., Humphrey, A. E. \& Krawiec, S. (1996). Kinetic analyses of desulfurization of dibenzothiophene by Rbodococcus erythropolis in continuous cultures. Appl Environ Microbiol 62, 3066-3068.

Received 30 January 1998; revised 26 May 1998; accepted 11 June 1998. 